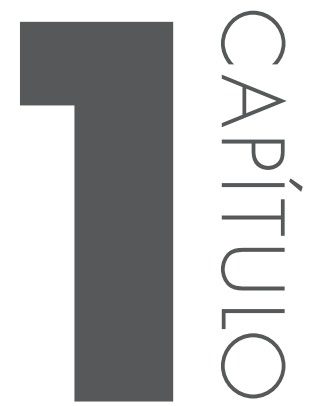

\title{
O TRABALHO DOCENTE NO CONTEXTO DA EDUCAC̣ÃO INFANTIL E A PERSONALIDADE COMO FENÔMENO SOCIAL
}

Silva, Bráulio Ramos '; Silva, Altina Abadia da ${ }^{2}$

' Universidade Federal de Goiás - UFG/RC

*email: brauliokaue@yahoo.com.br

\section{RESUMO}

Esse texto é resultado de uma profícua incursão realizada no universo do referencial marxista, jornada que foi iniciada graças aos estudos proporcionados pela minha dissertação de mestrado que agora encontra-se em fase final de análise dos dados e de sua redação, esta que buscou compreender o trabalho docente e sua relação com o fenômeno da personalidade desse sujeito que é o professor da educação infantil. Aqui nesse pequeno recorte, coloca-se como objetivo, a apresentação do conceito de Personalidade segundo o materialismo histórico-dialético, buscando aos poucos, pensar sua relação com o trabalho docente, ou seja, arrazoar as repercussões da constituição desta individualidade 
humana a partir das atividades produtivas relacionadas à docência no contexto da educação infantil. Ao longo do documento perceberemos que a personalidade é determinada por multíplices fatores e o trabalho é um dos principais determinantes, e ao pensarmos um sujeito assim como uma personalidade concreta, tomemos as palavras de Marx quando este coloca que "o concreto é concreto por ser uma síntese de múltiplas determinações, logo, unidade da diversidade" (MARX, 1973, p. 229), ou seja, ainda que não esqueçamos que nosso sujeito é o conjunto das relações sociais, produto e produtor do gênero humano, portanto, sujeito às várias determinações histórico-sociais, a atividade por ele realizada, principalmente sua docência, esse elemento fundamentalmente humanizador, muitas vezes está sujeito aos riscos de entregar-se às práticas ritualizadas, às relações sociais reificadas e p or fi $\mathrm{m}$, cu lminar na cr escente fetichização da personalidade que por vezes contribui para o esvaziamento do trabalho do professor.

Palavras-chave: Trabalho docente; personalidade; educação infantil.

Revisado pela Orientadora Altina Abadia da Silva, contato: tina@wgo.com.br

Silva, Bráulio Ramos; Silva, Altina Abadia da; "O TRABALHO DOCENTE NO CONTEXTO DA EDUCAÇÃO INFANTIL E A PERSONALIDADE COMO FENÔMENO SOCIAL", p. 11-28 . In: Seminário de Pesquisa, Pós-Graduação e Inovação da Regional Catalão (2. : 2014 : Goiás) Coletânea Interdisciplinar em Pesquisa, Pós-Graduação e Inovação - Volume 2 : Humanidades e Letras. Anais [livro eletrônico] / organizado por Adriana Freitas Neves, Idelvone Mendes Ferreira, Maria Helena de Paula, Petrus Henrique Ribeiro dos Anjos. São Paulo: Blucher, 2015. ISBN: 978-85-8039-111-4, DOI 10.5151/9788580391114-V2_Cap1 


\section{INTRODUC̣ÃO}

Este texto é um recorte da pesquisa intitulada "O trabalho docente e a identidade do professor de educação infantil” registrada no Comitê de Ética sob o n. ${ }^{\circ} 694.039$ que teve como objetivo geral a identificação e análise dos sentidos que ganham o trabalho docente na concepção de quatro professoras de um CMEI de Itumbiara-GO. Desdobrou-se do objetivo geral outros três objetivos mais específicos, são eles: a) identificar e analisar a concepção de trabalho docente das professoras; b) identificar e analisar os sentidos atribuídos a natureza humana (criança) a ser transformada pelo professor durante $o$ trabalho docente; e, c) cotejar a relação entre trabalho docente e os processos de humanização/alienação.

Aqui nesse recorte, procuraremos apresentar o fenômeno da personalidade segundo o referencial marxista, que é um dos conceitos-chave deste estudo, em seguida, identificaremos as propriedades dessa personalidade, dentre elas, as capacidades, buscando problematizar o desenvolvimento destas capacidades em função das necessidades como forma de pensar o desenvolvimento da personalidade alargada, e por fim, discutiremos os perigos presente no discurso neoliberal e no imediatismo para o desenvolvimento da personalidade que por vezes leva ao surgimento do fenômeno do fetichismo da personalidade e de seus desdobramentos para o trabalho docente.

\section{A PERSONALIDADE COMO UM FENÔMENO CONSTITUÍDO SOCIALMENTE}

As incursões da Psicologia clássica nos problemas sociais apresentamse infecundas quando verificada sua incapacidade de produzir mudanças na superação das desigualdades sociais, também a jura em se centrar na subjetividade humana como forma de compreender suas mazelas, levadas sob tais perspectivas a-históricas, não teria outro ensejo que não resultados estéreis obtidos por forças totalmente dissipadas.

A lógica neoliberal apregoou certo tipo de culto da subjetividade humana, um discurso que não pode ser assumido na forma de negação da sociedade burguesa; pelo contrário, põe-se na verdade, ser vista como sua reafirmação. Pensando no professor, profissional responsável pela humanização das novas gerações - este que é muitas das vezes foco e alvo dos discursos que inflamam o fazer docente e seu alcance de mudança da sociedade -, destacamos a urgente necessidade de entender a constituição da personalidade, especialmente a 
personalidade do professor em meio a esta "sociedade globalizada, guiada pelo ideário neoliberal” (FACCI, 2004, p. 61).

$\mathrm{Na}$ sociedade em que vivemos, esta que se encontra subjugada pela lógica do capital e pelas relações reificadas, há-se os riscos de tomar a subjetividade em sinal de reverência, num verdadeiro movimento de fetichização que contribui para o esvaziamento do trabalho enquanto atividade vital. No caso do trabalho docente, este que é realizado entre pessoas e que tem como finalidade a humanização e não produção de mercadorias, elevar a subjetividade a um patamar sacralizado, tão distante da constituição própria que é a de ser formada pelas interrelações sociais, acaba por lhe conferir poderes mágicos e tamanho distanciamento que enfraquece o poder da atividade de humanização possibilitada por esta atividade. Quando Marx (1968, p. 81) nos diz que "uma relação social definida, estabelecida entre os homens assume a forma fantasmagórica de uma relação entre coisas" ele nos remete à esta ideia de fetichização da mercadoria que é tão nociva para as relações de emancipação, é como se a reificação produzida pelas relações objetivadas encobrisse as características sociais do trabalho humano. Segundo esse mesmo autor, fetichismo é esse fenômeno “[...] que está sempre grudado aos produtos do trabalho quando são gerados como mercadorias. É inseparável da produção de mercadorias”.

Sobre a fetichização, Silveira (1989) afirma que a sujeição a este tipo de alienação envolve o ser humano da forma mais profunda possível, por estar o sujeito de forma direta e constante em ligação com o social, e esse fenômeno acaba por se inserir na própria estruturação psíquica do indivíduo. Aos poucos, a fetichização da individualidade apropria-se de tal forma da personalidade do ser humano que acaba por conferir à sua individualidade, assim como à sua personalidade, poderes mágicos e alheios ao seu controle.

Os riscos anunciados e discutidos acima são provenientes dos processos de alienação pelo qual os sujeitos têm sido submetidos, e são também reforçados pelas ideologias sustentadas por construções teóricas que naturalizam os processos de dominação. Nesse caminho tomemos o exemplo das correntes hegemônicas da Psicologia que têm tomado a Personalidade em seus estudos quase sempre como um fenômeno constituído sem interferências da realidade externa, ou seja, como elemento a-histórico, que se constitui a priori, a partir do desenrolar de processos próprios. Essa perspectiva em nada tem contribuído para elucidar o estudo sobre o gênero humano, pelo contrário, tem cooperado para a manutenção de explicações causais sobre as desigualdades e atrocidades verificadas ao longo da história da humanidade. Segundo Martinez (1989, p. 64 apud Filho \& Guzzo 2009, p. 46), essas correntes psicológicas têm utilizado duas maneiras os conhecimentos provenientes dessa área de saber, uma "que 
absolutiza o processo de interação clínica, como uma via essencial para estudar a personalidade; outra que enfatiza a necessidade de se aplicar instrumentos para acessar a personalidade".

Estas escolas psicológicas que se atêm à perspectiva a-históricas do desenvolvimento da personalidade têm valoração privilegiada pela ciência psicológica clássica e vêm orientando a intervenção em relação a seu objeto que é o homem. Em consequência, ao privilegiarem o isolamento do humano a fim de estudar sua personalidade, considerando-o assim descolado do social, negligenciam seu movimento constituidor e interativo. Por outro lado, quando supervalorizam os instrumentos de mensuração e de acesso a esta suposta "personalidade", novamente desconsideram a dinamicidade e sociabilidade de tal fenômeno.

Compreender a Personalidade sob outra perspectiva implica apreender a realidade sob um novo olhar, requer pensar a realidade humana como algo construído pelo próprio homem, gestado por este, inclusive as propriedades de sua própria psique. Mas não significa com isso dizer que o homem assim o faz independentemente, descolado, pelo contrário, que este só o consegue em íntima relação dialética com o outro, com o social que lhe é inerente.

Pino (2000) cita Vigotski na afirmação de que "o homem é uma pessoa social. Um agregado de relações sociais encarnadas num indivíduo”, ainda, que "a natureza psicológica do homem é a totalidade das relações sociais transferidas à esfera interna e tornadas funções da personalidade e formas da sua estrutura" (Vigotski, 1989, p. 59 apud PINO, 2000, p. 47).

Esse intercâmbio entre a esfera interna e externa ocorre de forma constante e dialética, e desconsiderar esses elementos para o estudo da personalidade faria incorrer em erro epistemológico. É isso que alerta-nos Vigotski (1999) citado por Filho \& Guzzo (2009) ao se referir às linhas de ruptura e continuidade na relação dialética entre essas esferas humanas, pois o ser humano, ao se apropriar conscientemente do objeto e o transformá-lo, rompe com sua continuidade, ou seja, com aquilo que a realidade objetiva ofereceria pronto, conferindo-se à esta, a possibilidade de continuar realidade subjetiva, ainda que resguardando os elementos constituintes do objeto.

A personalidade humana é social e por isso não se define num determinado momento ou fase da vida, permanece aberta assim como é a relação do homem com a natureza, segundo Marx, citado por Mészáros (1979), o homem é "um ser natural" e "como ser natural vivo, dotado, de um lado, de poderes de vida naturais; é um ser natural ativo"; portanto, existem forças nele que são peculiares, "essas forças existem nele como tendências e capacidades; como impulsos"; e, "como ser natural, corpóreo, sensível, objetivo, ele é uma 
criatura sofredora, condicionada e limitada, como os animais e plantas". Por conseguinte os objetos existiriam fora dele, alheios a seus impulsos agonizantes, mas, apesar disso, objetos de sua necessidade, essenciais e indispensáveis à sua existência. (MÉSZÁROS, 1979, p. 151).

Compreender a relação entre o ser humano e os objetos, ou seja, entre ele e a natureza, e, como este satisfaz suas necessidades, é uma questão fundamental para entender profundamente a relação entre o homem e a atividade. Por sua vez, abrange não somente sua relação com a natureza, mas, de forma basilar, o nexo da infraestrutura de sua personalidade.

Não basta admitirmos a premissa fundante do materialismo históricodialético de que, para haver história, os homens devem estar em condições de viver para "poder fazer história", e que para viver seria preciso, antes de tudo, comer, beber, ter habitação, vestir-se e algumas coisas mais, ou seja, apropriar-se dos objetos e transformá-los via produção dos meios que permitem a satisfação das necessidades, o que Marx e Engels (1996) definem como "produção da própria vida material”. É preciso, para além de tal admissão, perfazer a estrita compreensão da relação entre as atividades que possibilitaria a satisfação destas necessidades ao longo de determinado tempo e, por sua vez, que possibilitaria o surgimento de outras necessidades, inclusive a necessidade de mais tempo (MARX; ENGELS, 1996, p. 39 apud FACCI, 2004 p. 158).

Isto nos leva a afirmar de início que sendo os objetos, externos, e havendo a necessidade de estabelecer com eles uma relação de apropriação, "não obstante, esses objetos são objetos de sua necessidade, são essenciais, indispensáveis à manifestação e à confirmação de seus poderes essenciais”. Com isso, Marx, citado por Mészáros (1979, p. 151), afirma a interrelação entre o sujeito e o objeto, a qual não é, porém, unilateral, e sim dialética, pois "tão logo eu tenho um objeto, ele tem pra mim um objeto”. Isto é, há uma dupla constituição, tanto do objeto, que é pelo sujeito transformado, quanto do sujeito que o toma. Segundo Mészáros (1979, p. 151), "considerada nesse nível, minha relação com meus objetos é a mesma que entre objetos naturais não-humanos."

Dessa maneira, compreender a constituição da psique humana a partir da interrelação com o social é pressuposto fundamental para encadear as demais considerações acerca de uma realidade humana que se coloca de forma dialética, portanto, histórica. Segundo Mészáros (1979, p. 151), “um ser que não tem sua natureza fora de si mesmo não é um ser natural e não desempenha qualquer papel no sistema da natureza". Esta afirmação corrobora a prerrogativa da condição social do ser humano em constante interação com um outro; de outra forma, "um ser que não é em si um objeto para outra pessoa não tem ser para seu objeto; isto é, não está relacionado objetivamente. Um ser não-objetivo é 
uma nulidade, um não-ser” (MÉSZÁROS, 1979, p. 151). Portanto, qualquer estudo acerca da personalidade precisa partir dessa premissa a fim de dar conta da complexidade que é o fenômeno humano.

Para Marx citado por Leontiev (1978, pp. 267-268) o homem é um ser social, e nisso consiste dizer que ele se constitui socialmente, mas não somente a linguagem e as funções mentais superiores, além disso,

[...] a visão, a audição, o olfato, o gosto, o tacto, o pensamento, a contemplação, o sentimento, a vontade, a atividade, o amor, em resumo, todos os órgãos da sua individualidade que, na sua forma, são imediatamente órgãos sociais, são no seu comportamento objetivo ou na sua relação com o objeto a apropriação deste, a apropriação da realidade humana (LEONTIEV, 1978, pp. 267268).

Essa apropriação se dá pelo ato e aqui o termo se difere explicitamente do que comumente poderíamos entender por conduta ou função, mas como nos propõe Sève (1979), carrega em si o desvelar de uma capacidade que incide no tempo e manifesta o humano por se fazer. Antes disso, Marx e Engels, na "Ideologia Alemã", lançam essas bases quando afirmam que "o ser dos homens é o seu processo de vida real" (MARX, 2007, p. 50). Com isso refutamos qualquer base psicológica que se firme no estudo da tipologia da personalidade, não sendo possível considerar esta Psicologia uma psicologia concreta. Para que uma psicologia concreta seja realmente possível, criticamente falando, seu estudo deve pautar-se na topologia da personalidade humana como análise concreta das "estruturas e da lógica de desenvolvimento que resultam de um conjunto de actividades de um indivíduo. A começar pelas suas atividades sociais de base, pelo seu trabalho concreto" (SÉVE, 1979, p. 428).

Séve (1979), retirando da obra de Politzer "La crise de la psychologie contemporaine" os argumentos que possibilitam o clareamento do conceito de ato, o define como todo tipo de comportamento a presentado pelo indivíduo, seja ele de cunho mais abstrato, relacionado ao psiquismo, seja relacionado à atividade concreta, capaz de constituir o material de sua biografia. Dito de outra forma, é ato "enquanto produz (eventualmente) um certo número de resultados, não só resultados para o usufruto do próprio indivíduo e obtidos de forma directa, como também resultados para o usufruto da sociedade". Dessa forma, os atos circunscrevem o universo da produção humana que compõe sua história, “são os elementos pertinentes da biografia”. Um a to é, então, uma manifestação do próprio indivíduo, de sua particularidade, uma "expressão de 
si”; mas não somente inclui nessa manifestação “o acto de um mundo social determinado, um aspecto das relações sociais, uma expressão das condições históricas obcjetivas" (SÈVE, 1979, pp. 436-437).

$\mathrm{O}$ ato em si integra o ser humano à sua genericidade, determina sua condição social pertencente a uma realidade, reflete tanto a individualidade de sua existência quanto a universalidade de sua condição de ser social. É esta a contradição presente na constituição da personalidade humana que precisa ser desvendada, analisada caso se queira compreender o homem em sua totalidade, assim deve proceder uma psicologia concreta da personalidade.

A análise dessa atividade pressupõe a infraestrutura da personalidade, compreende assim o teor objetivo da atividade real deste indivíduo concreto, concretude manifesta em suas realizações, ou seja, na materialização de sua existência que perpassa sua existência num sistema de base temporal, configurando-se, portanto, uma personalidade desenvolvida. Segundo González Rey e Mitjans (1989, p.9), a personalidade, tomada sob esta perspectiva, é responsável por "mediar a relação entre a atividade e a consciência" e, só por isso, tem a capacidade de conferir caráter social ao gênero humano.

Poderíamos concluir que a infraestrutura de uma personalidade desenvolvida reside na estrutura de sua atividade, nesse sistema cuja substância é o tempo, "porque apenas uma estrutura temporal pode ser homogénea relativamente à lógica interna da atividade de um indivíduo, da sua reprodução e do seu desenvolvimento" (SÈVE, 1979, p. 466). O maior equívoco da psicologia clássica ao tomar o fenômeno da personalidade é não conseguir apreender a temporalidade como fator preponderante no desenvolvimento da psique humana, desconsiderando-se assim os determinantes singulares da inserção do sujeito em sua própria historicidade.

A topologia da personalidade, na qualidade de estrutura dialeticamente constituída, possui movimento histórico e revela sua própria lei de funcionamento a partir da unidade estrutural de funcionamento do homem concreto, de sua atividade real ao longo de sua existência como personalidade singular. Sobre esse desenvolvimento, Sève (1979) destaca a necessidade de realizar uma "topologia geral do emprego do tempo", ou seja, uma análise das atividades em relação à administração deste tempo, o que forneceria material "à ciência empírica das personalidades singulares” (SÈVE, 1979, p. 467).

Não são todas as atividades que resultam na constituição da personalidade, dentre elas, aquelas que são objetivamente infraestruturais, as “psicologicamente produtivas", e por produtivo nos balizamos em Marx quando este nos diz que só é produtivo a atividade produtiva que oferece riqueza para o capital; e, também, as atividades que buscam a satisfação imediata das necessidades, 
ou seja, as atividades voltadas para si, seriam esses dois tipos de atividades as capazes de produzir e reproduzir a personalidade.

Na primeira categoria, o das atividades socialmente produtivas representase a atividade abstrata, "facto que constitui igualmente o essencial do seu caráter psicologicamente produtivo: é sobretudo através do poder de compra do salário que o trabalho assalariado intervém na produção e reprodução da personalidade". Já na outra categoria de atividades, daquelas que visam à satisfação imediata das necessidades humanas, assim como a aprendizagem de novas capacidades (setor I) alheias a qualquer relação com o exercício do trabalho social, estas são denominadas “atividades concretas” (SÈVE, 1979, p. 473).

A lógica imposta pelo capitalismo na qual o ser humano está inserido, como coloca Martins (2011) de que estamos todos inseridos sem a chance de nos esquivar, impõe ao ser humano a possibilidade de cindir-se de sua atividade, na qual o trabalho por ele realizado não mais representa o aspecto vital de sua constituição, tão somente significa abstração de seu ser. Com isso, a atividade social abstrata por ele desenvolvida, esta que também enriquece o capital, constituiria sua personalidade abstrata enquanto que sua atividade pessoal concreta seria responsável pelo desenvolvimento de outro tipo de personalidade, sua personalidade concreta. Nesse preâmbulo, podemos verificar emergir o conceito de necessidade de tempo, que é um dos produtos desta cisão da personalidade do homem, fruto da separação entre a personalidade abstrata e personalidade concreta, alheamento provocado pela lógica imposta pelo capitalismo, lógica que atua e vem, "servindo-se de bisturi invisível, operar na nossa própria alma, a crítica de um modo de vida que exige o sacrifício da vida pessoal concreta à vida social abstrata", tudo isso, em face da reprodução do sistema" (SÈVE, 1979, p. 475).

A fim de continuarmos a discussão acerca da constituição da personalidade sob um enfoque social, façamos uma pequena menção aos aspectos superestruturais da personalidade, pois, mesmo que estes fatores sejam responsáveis apenas pela regulação da personalidade, pensar a superestrutura da personalidade poderá auxiliar-nos na compreensão do movimento de despersonalização a que tem sido submetido o ser humano e, por conseguinte, o professor.

Tal movimento de despersonalização pode ser compreendido como a transferência de um vínculo afetivo pela racionalização da relação, isto é o que tem ocorrido frequentemente e pode ser percebido quando as relações sociais são objetivadas e submetidas às dissimulações, às relações de poder que subjugam uns aos outros comprometendo consubstancialmente a relação entre 
as pessoas. No caso do professor e seus alunos, esse movimento é duplamente prejudicial, visto que incide diretamente no processo de humanização.

Pensar a superestrutura é pensar as particularidades do sujeito em seu modo de ser mais autêntico, sem que isso signifique necessariamente a utenticidade. Conforme SEVE (1979), a superestrutura manifesta a singularidade do sujeito, seja por seus atos singulares, seja pelas respostas emocionais às situações cotidianas de sua vida. A superestrutura, ao contrário da infraestrutura, possui as particularidades de um jeito único de ser conseguido pela forma que o indivíduo se coloca no mundo objetivo, compreende "a unidade dialética entre objetividade e subjetividade, corresponde à manifestação da personalidade propriamente dita, caracterizando a singularidade do sujeito", sua mais própria unicidade, "ainda que estas características pessoais estejam situadas em uma realidade histórica construída a partir da cisão entre capital e trabalho" (SÈVE, 1979 , p. 368).

Juntas, infraestrutura e superestrutura compõe a personalidade, tendo a consciência e a atividade como eixos fundantes e organizadores do ato, portanto, da infraestrutura, e os aspectos emocionais e regulatórios, conferindo forma a partir da superestrutura.

\section{AS PROPRIEDADES DA PERSONALIDADE E 0 TRABALHO DOCENTE}

Procurando compreender um pouco mais sobre a personalidade, adentremos suas propriedades, a saber, falemos mais detalhadamente do temperamento, do caráter e das capacidades como domínios pertencentes a este fenômeno historicamente constituído (SMIRNOV et. al. 1960, pp.433-462 apud MARTINS, 2011, p. 93).

Sobre estas propriedades, vale ressaltar o fato de que há constantemente um intercâmbio entre as determinações biológicas e os condicionantes sociais na constituição de tais características. O temperamento, talvez uma das propriedades da personalidade mais sujeitas à determinação biológica, portanto relativamente estável, ainda assim se encontra sujeito a modificações causadas pela constante interrelação com a realidade externa. Sempre que houver alguma referência a características da personalidade ligada a disposições neurofisiológicas e bioquímicas que se manifestem mediante certa estabilidade, ou àquelas ligadas aos elementos emocionais, estaremos tratando dos componentes da personalidade relacionada ao temperamento.

Leontiev (1978), quando fala sobre o papel da atividade nervosa 
superior na determinação da personalidade do indivíduo, afirma que e sta atividade nervosa não tem a capacidade de determinar as particularidades dessa personalidade, ou seja, definir suas especificidades. Ainda segundo este autor, mesmo que haja desequilíbrio da atividade nervosa superior, e esta afete a relação do indivíduo com o mundo, interferindo na diversidade de seu papel e na formação de sua personalidade, ainda assim não poderíamos conferir somente a este fator, somente à neurofisiologia, ou seja, ao cérebro propriamente dito, a definitiva determinação da constituição da personalidade humana.

Outra propriedade desta personalidade é o caráter que, segundo Smirnov (1960), "representa a combinação de características individuais distintas de uma pessoa como membro de um grupo social, manifestandose em todos os seus comportamentos e relações com o mundo circundante" (SMIRNOV et al, 1960, p. 463 apud MARTINS, 2011, pp. 102-103). Esse mesmo autor enfatiza que o caráter é algo que se constitui ao longo da vida e que está fortemente carregado de influências sociais, ou seja, assim como o caráter pode ser tomado como uma extensão dos valores sociais de determinada cultura - resguardando-se, portanto, uma dimensão ideológica fundada em valores, ideias pelas quais o indivíduo direciona suas ações -, conclui-se também que tal caráter pode ser redirecionado, reeducado mediante influência social, mesmo que para se alcançar algum resultado seja necessário dispender enorme energia e trabalho. O importante a considerar é que o caráter não é algo dado a priori, nem estanque. Assim, tanto temperamento quanto caráter, na condição de propriedades da personalidade, atuariam como formadores sensivelmente permeáveis às influências sociais.

A terceira propriedade da personalidade guarda predicados interessantes e não só nos ajudará a compreender melhor este construto como também lançará amarras em direção ao vínculo da atividade em relação ao emprego do tempo, ou seja, aos atos singulares definidores da personalidade.

Por atos singulares da personalidade compreendemos "aqueles que geram movimentos históricos, avanços e retrocessos na relação entre subjetividade e objetividade", ou seja, demarcam posição particular do indivíduo em determinado momento histórico, exprimem as contradições entre idealização e realização efetiva da atividade, colocando em movimento todo um processo criador humano de auto-superação (SÈVE, 1979, p. 448).

As capacidades humanas são derivadas da divisão e especialização do trabalho, da evolução proporcionada pelo condicionamento histórico-social; assim entendemos que "as capacidades não são dons do indivíduo, mas produtos da história humana (SMIRNOV et al. 1960, pp. 434-435 apud MARTINS, 2011, p. 98). 
Cada situação, cada atividade realizada em determinado tempo segundo determinada condição, confere ao indivíduo que a realiza condições específicas pelas quais suas propriedades psicológicas individuais serão colocadas a se diferenciar, assim como suas capacidades. Nesse sentido, cada atividade requer determinado conjunto de processos psíquicos, que serão aplicados de tal forma, mostrando-se as capacidades humanas tal qual as apresentamos até aqui.

O conceito de capacidade representa tamanha importância para a constituição da personalidade que Sève (1979) admite ser este o segundo conceito base para a teoria da personalidade; o primeiro seria o conceito de ato, e sobre o conceito de capacidade este autor vai buscar na obra "Contribuição" de Marx a argumentação para fundamentar sua afirmativa. Segundo Marx, o "trabalho não objetivo", este que ainda não se encontra materializado, efetivado pela ação do homem, existe em forma de capacidade, "existe temporalmente, não pode existir senão sob a forma de capacidade, de possibilidade, de faculdade, de capacidade de trabalho do sujeito vivo"; ou seja, a capacidade humana não só se coloca como algo apropriado pelo homem a partir de sua relação com a natureza, mas sua existência se encontra na própria natureza a ser transformada (SÈVE, 1979, p. 438).

A relação dialética entre a capacidade e o ato requer atenção para que esse movimento seja apreendido corretamente, pois a capacidade se coloca como condição individual para a efetivação do ato, ao mesmo tempo em que algumas capacidades só são possíveis pelo conjunto dos atos que as produzem. Sobre esse ciclo ato-atividade ou atividade-ato - ambos constituídos de um mesmo ciclo de atividade, no caso, a atividade geral do indivíduo - desdobram-se dois setores fundamentais que mantêm relações de reciprocidade entre si.

Sève (1979) denomina de Setor I e Setor II esses dois setores, o Setor I referindo-se às atividades responsáveis pelo "conjunto de atos que produzem, desenvolvem ou especificam determinadas capacidades”, e o Setor II ao "conjunto dos atos, que colocando unicamente em ação as capacidades já existentes, produz tal ou tal resultado a que o exercício dessas capacidades permite que cheguemos" (SÈVE, 1979, p. 439).

O autor supracitado faz uma ressalva ao fato de que essa divisão das atividades nesses dois setores muitas vezes é mais facilmente conseguida no aspecto teórico, já que algumas atividades podem corresponder aos dois setores simultaneamente, isto porque são inúmeras as situações em que há o duplo pertencimento, no qual as atividades são ao mesmo tempo situações de aprendizagem e também exercícios de capacidades. O que nos interessa aqui, nesse instante, é salientar que, para a análise criteriosa da personalidade, esta distinção precisa ser compreendida, entendendo-se que há uma lógica no movimento 
entre os setores I e II na qual deve haver uma relação de proporcionalidade a ser mantida a fim de se manter o equilíbrio da referida personalidade. $\mathrm{O}$ autor discute o movimento de quebra dessa proporcionalidade, no qual haveria um descompasso entre os setores I e II, em que o aumento considerável das atividades (Setor II), que colocariam as capacidades em curso, interferiria diretamente na produção das necessidades sem que novas capacidades (Setor I) fossem desenvolvidas para a satisfação das tais necessidades.

Ao pensarmos a questão da reprodução alargada da personalidade em relação ao professor da educação infantil admitimos que esta ocorre em meio a um processo fundamentalmente social, em que se interliga a formação do indivíduo não só ao ambiente de trabalho, mas também a todas as esferas de sua vida cotidiana.

Segundo Basso (2002), “as condições subjetivas são próprias do trabalho humano, pois este constitui-se numa atividade consciente"; e estas condições precisam ser consideradas ao estudar a formação do professor, pois determinada situação interfere diretamente em como esse sujeito atribui significado à sua atividade. Ao se referir às condições objetivas, faz-se menção à organização prática das atividades, sejam elas referentes ao planejamento das aulas, sejam as condições relacionadas com as políticas educacionais de remuneração salarial (BASSO, 2002, p. 2 apud FACCI, 2004, p. 13).

Percebemos que, ainda que as esferas subjetivas e objetivas sejam apreendidas separadamente pela lógica cartesiana, ambas perfazem uma relação dialética na constituição do indivíduo e atuam indissociavelmente na constituição da personalidade dos sujeitos, sejam eles engenheiros, lavradores ou professores.

Exige-se esforço para apreender a personalidade para além das aparências e do imediatismo, assim como é necessária diligência para analisar o ser humano a partir de sua atividade. Como nos propõe Marx, "definir o homem por meio do trabalho é defini-lo por meio de uma generalidade abstrata, logo, desde o início, é afastarmo-nos do materialismo dialético e histórico" (SÉVE, 1979, pp. 456-457). Sendo a personalidade constituída a partir de múltiplos fatores, sujeita aos mais variados determinantes, é preciso tomar o ser humano em sua integralidade, buscar apreender seus atos singulares nos mais diversos contextos e não somente a partir de sua atividade produtiva, ou seja, de seu trabalho. Com isso, reafirmamos que tomar o homem apenas pela ótica de sua atividade produtiva, é também relacionar-se com o trabalho sob sua aparência, buscando tão somente nesse homem uma essência psicologizada do homem abstrato. Recordemo-nos que o marxismo e o comunismo requerem tão efusivamente o fim deste trabalho abstrato em favor de uma atividade vital humana que 
possibilite ao homem se realizar em seu fazer, que seus atos engendrem uma lógica produtiva com suas capacidades, que seu enriquecimento pessoal possa ocorrer de tal forma que não esteja subjugado pelo enriquecimento do capital, somente assim, quando o trabalho for realmente emancipado, o desenvolvimento da personalidade alargada caminhará em consonância com a atividade desenvolvida pelo sujeito.

Segundo Marx, citado por Sève (1979), o trabalho só se pode emancipar quando

[...] $1 .^{\circ}$, o seu conteúdo social estiver assegurado; $2 .^{\circ}$, se revestir um caráter científico e surgir diretamente como sendo tempo de trabalho geral; por outras palavras, de deixar de ser esforço do homem, simples força natural do estado bruto que suportou uma determinada domesticação, para se tornar na actividade do sujeito que regulamenta todas as forças da natureza no seio do processo de produção (SÈVE, 1979, p. 459).

Não é isso que temos percebido na atividade realizada no contexto das instituições de ensino, não é também aquilo que reflete os dados de pesquisa com os quais temos nos deparado.

Defendemos aqui, que o trabalho docente no contexto da educação infantil, realizado na rede pública, é sim trabalho produtivo, produz mais-valia e como toda atividade que possibilita a produção de sentido, fornece material para construção da subjetividade e, por conseguinte, atua para a constituição da personalidade daqueles que ali realizam trabalho.

Gonçalves (1996), citada por Facci (2004), se refere ao descuido havido nos cursos de qualificação e formação do professor por negligenciarem os relatos que envolvem a relação entre a subjetividade dos docentes e a sua prática docente (FACCI, 2004, p. 22). Por outro lado, o movimento contrário é também perigoso: as formações que se fundamentam em teorias que conferem destaque ao processo educativo, em que se valorizam apenas as experiências e a reflexão sobre a prática - portanto, demasiado subjetivistas, "correm o risco de apenas analisar a subjetividade do professor como se esta fosse produzida na particularidade, ou mesmo entre seus pares, desconectada da realidade social" (FACCI, 2004, p. 54).

A dialética anunciada pela proporcionalidade na relação entre atos e capacidades nos aponta que a profissão docente possui momentos de singularidade e universalidade; a primeira, que é compreendida pela identidade pessoal do professor, formada por seus posicionamentos políticos e ideológicos 
frente ao mundo; já sua universalidade apresenta-se na forma pela qual o indivíduo se associa a outros indivíduos a partir de suas filiações políticas, ou seja, como "mediadora das condições empíricas singulares com a sociedade, com aspectos de uma particularidade que é a categoria profissional ocupando um espaço social” ( SOUZA, 1993, p. 71-72 apud FACCI, 2004, p. 25).

\section{CONSIDERAC̣ÕES FINAIS}

Buscando fazer alguns apontamentos no sentido de concluir as discussões realizadas aqui partimos da afirmativa de que o trabalho educativo realizado pelo professor na forma de processo de humanização, pressupõe o homem diante de outro homem do qual jamais poderá estar alienado, ou seja, o professor não poderá sentir alheamento em relação a este outro que pretende transformar, humanizar. Portanto, esta relação de ordem interpessoal, tem sua base na mediação de apropriações e objetivações realizadas pelos indivíduos partícipes desse encontro, no qual as singularidades e universalidades permeiam a dupla transformação colocada em curso, processos que atuam para a constituição da personalidade tanto do professor quanto das crianças que também atuam nesse processo.

Como foi possível verificar, são muitos os aspectos que incidem para a composição da personalidade do ser humano e o trabalho é apenas um deles, e, ao nos referirmos especificamente à personalidade desse sujeito que é o professor, não podemos nos esquecer de que esta constituição perpassa a discussão da necessidade por identificação com a atividade realizada, da relação consciente com os objetivos do processo, da

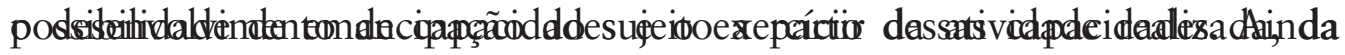

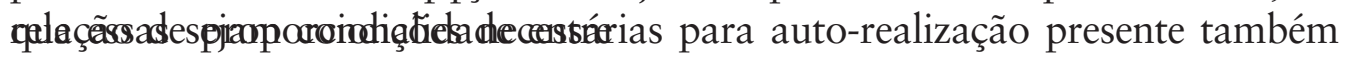
em outras atividades produtivas, em outras profissões, no caso específico do professor, segundo coloca Nóvoa (1995, p. 17 apud FACCI, 2004, p. 28) ao se referir à atividade de ensino, "a maneira como cada um de nós ensina está diretamente dependente daquilo que somos como pessoa quando exercemos o ensino", sendo, portanto, "impossível separar o eu profissional do eu pessoal" (NÓVOA, 1995c, p. 17).

Quando Canário (1997 p. 12 apud MARTINS, 2011, p. 20) enfatiza que o professor se enquadra dentre os profissionais que exercem uma atividade de ajuda, isso nos aponta para o fato de que ele estabelece relação direta com aquele que pretende ajudar, por isso, este professor investe toda sua energia emocional, 
aplica toda sua personalidade e se sujeita aos níveis de stress elevados, haja vista a enorme carga emocional e alto nível de frustração associado à sua atividade. "A consequência do fato de o professor ser, em primeiro lugar, uma pessoa, é que a natureza de sua atividade se define tanto por aquilo que ele sabe, como aquilo que ele é".

Essas colocações reforçam nossa premissa de que o conceito da personalidade precisa ser mais bem compreendido e trabalhado dentro de seus determinantes histórico-sociais, problematizado segundo suas principais propriedades, ou seja, o temperamento, o caráter, e quanto às capacidades, cuidar para que estas sejam desenvolvidas em equilíbrio com a satisfação das necessidades. 


\section{Title: THE WORK OF TEACHERS IN THE CONTEXT FROM THE CHILDREN EDUCATION AND THE PERSONALITY AS A SOCIAL PHENOMENON}

\section{Abstract}

This text is the result of a fruitful raid carried out in the Marxist framework universe journey that began thanks to the studies provided by my dissertation now is in the final stages of data analysis and his essay, it sought to better understand the teaching and its relation to the personality of the phenomenon that guy who is professor of early childhood education. Here in this small cutout, is but the objective presentation of the concept of the personality according to the historical and dialectical materialism, seeking slowly, thinking their relationship with the teaching, that is, to reason the impact of the creation of this human individuality from productive activities related to teaching in the context of early childhood education. Throughout the document realize that personality is determined by factors Bundled and the work is a major determinant, and to think a guy like that as a concrete personality, let us take Marx's words when he states that "the concrete is concrete because it is a synthesis of multiple determinations, hence the unity of diversity "(MARX 1973, p. 229), that is, yet we forget that our subject is the set of social relations, product and producer of mankind, therefore, subject to various historical and social determinations, the activity performed by him, especially his teaching, this element fundamentally humanizing often is subject to the risks of delivering to the ritualized practices, the reified social relations and ultimately lead to the growing fetishization of personality by often contributes to the emptying of the teacher's work.

Keywords: Teaching; personality; childhood education. 


\section{REFERÊNCIAS}

DUARTE, Newton. 0 Bezerro de Ouro, 0 fetichismo da mercadoria e o fetichismo da individualidade. In: DUARTE, Newton (org.). Crítica ao fetichismo da Individualidade. 2. ed. rev. Campinas: Autores Associados, p. 1-18, 2012.

$\mathrm{FACCl}$, Marilda G. Dias. Valorização ou esvaziamento do trabalho do professor? Um estudo crítico-comparativo do professor reflexivo, do construtivismo e da psicologia vigotskiana. Campinas-SP: Autores Associados, 2004.

FILHO, Antônio Euzébios e GUZZO, Raquel Souza Lobo. Marxismo e teoria da personalidade: uma análise do sujeito histórico. Cadernos Cemarx, n. 6. p. 45-60, 2009.

GONZÁLEZ REY, Fernando e MITJÁNS MARTINEZ, Albertina. La personalidad: Su Educación y desarrollo. Habana: Pueblo y Educación, 1989.

LEONTIEV, A. N. 0 desenvolvimento do psiquismo. Lisboa: Livros Horizonte, 1978.

MARTINS, Lígia Márcia. A formação social da personalidade do professor: um enfoque vigotskiano. In:

Coleção formação de professores. 1. ed. Campinas, SP: Autores Associados, 2011. MARX, K. Contribuição para a crítica da economia política. Lisboa: Estampa, 1973.

. 0 Capital. Livro 1, vol. 1. Rio de Janeiro: Civilização Brasileira, 1968.

MARX, K. \& ENGELS, F. A Ideologia Alemã. 3. ed. São Paulo: Martins Fontes, 2007. MÉSZÁrOS, István. Marx: A teoria da Alienação. Rio de Janeiro: Zahar Editores, 1979.

PINO, Angel. 0 social e o cultural na obra de Vigotski. Educação e Sociedade. Revista Quadrimestral de Ciência da Educação. N. 71. 2. ed. p. (45-78), Campinas: Cedes, 2000.

SÈVE, Lucién. Marxismo e a teoria da Personalidade. v. 3. Lisboa: Livros Horizonte, 1979. 